Cleomar de Sousa Rocha, Olira Saraiva Rodrigues, Cláudia Helena dos Santos Araújo, Mary Aurora da Costa Marcon *

\title{
Cora em Cores
}

Cleomar de Sousa Rocha é Pós-doutorado em Tecnologias da Inteligência e Design Digital (PUC-SP); Pós-doutorado em Estudos Culturais (UFRJ); Pós-doutorado em Poéticas Interdisciplinares (UFRJ); Doutorado em Comunicação e Cultura Contemporâneas pela Universidade Federal da Bahia; Mestrado em Arte e Tecnologia da Imagem pela Universidade de Brasília; Graduação em Letras pela Faculdade de Educação Ciências e Letras de Iporá. Professor da Universidade Federal de Goiás; Coordenador do Media Lab da UFG. <cleomarrocha@gmail.com> ORCID: 0000-0003-0483-8380

Olira Saraiva Rodrigues é Pós-doutorado em Estudos Culturais pelo Programa Avançado de Cultura Contemporânea (UFRJ). Doutorado em Arte e Cultura Visual (UFG); Mestrado em Educação (PUC-GOIÁS); Graduação em Letras (UEG). Docente e pesquisadora da Universidade Estadual de Goiás e Coordenadora de Português para Estrangeiros do Programa Idiomas sem Fronteiras da Assessoria de Relações Externas da UEG. <olirarodrigues@gmail.com > ORCID: 0000-0003-2371- 3030
Resumo Esta pesquisa visa estabelecer relações entre os escopos técnicos e poéticos de intervenções realizadas no Museu Casa de Cora Coralina, na Cidade de Goiás, às margens do rio Vermelho, desvelando padrões tecnológicos, ressoados dos sentidos da poética da autora. Metaforicamente, os fluxos de consciência da escrita da autora soam como escapismo em suas memórias, em que o rio e a terra vermelha, elementos de sua casa, traduzem sua relação sanguínea, estritamente, visceral em sua essência. A terra, água e o ar, corados, representam, nessa interface, o triângulo da vida, sendo elementos centrais do ir-e-vir da poesia de Cora. Retratos da cor local, o percurso metodológico, de abordagem fenomenológica, transita por entre ruelas, becos e bicas, produzindo fervuras, murmúrios, ecoando e escoando poesias. A tecnologia, enquanto artefato cultural, se inscreve nessa retórica da poesia como simbiose entre as letras, versos, poesias e prosas da autora, além dos caminhantes que vislumbram um trajeto de vozes dissociantes na Cidade de Goiás.

Palavras chave Museu Casa de Cora Coralina, Projeto Expográfico, Tecnologias Poéticas.

\section{Cora in Colors}

Abstract This research aims to establish relationships between the technical and poetic scopes of interventions performed at the Casa de Cora Coralina Museum, in the city of Goiás, on the banks of the Rio Vermelho, revealing technological patterns resonated with the author's poetic senses. Metaphorically, the author's writing flows of consciousness sound like escapism in her memories, in which the river and the red earth, elements of her home, translate their strictly visceral blood relation into its essence. The earth, water and air, stained, represent, in this interface, the triangle of life, being central elements of the coming and going of Cora's poetry. Portraits of local color, the methodological path, with a phenomenological approach, travels through streets, alleys and spouts, producing boils, murmurs, echoing and draining poetry. Technology, as a cultural artifact, is inscribed in this rhetoric of poetry as symbiosis between the author's lyrics, verses, poetry and prose, as well as walkers who glimpse a path of dissociative voices in the city of Goiás

Keywords Casa de Cora Coralina Museum, Expographic Project, Poetical Technologies. 
Cláudia Helena dos Santos Araújo é Pós-doutoranda em Estudos Culturais pelo Programa Avançado de Cultura Contemporânea (UFRJ). Doutorado em Educação (PUC-GOIÁs). Mestrado em Educação (PUC-GOIÁS). Graduação em Pedagogia (UEG). Membro dos grupos de pesquisa KADJÓT e PANECÁSTICA. Docente e pesquisadora do Instituto Federal de Educação, Ciência e Tecnologia (IFG). Professora no Programa de Pós-Graduação - Stricto Sensu - em Educação Profissional e Tecnológica. <helena.claudia@gmail.com> ORCID: 0000-0003-2453-4456

\section{Cora Coralina e suas poesias}

Incrustada nos montes e montanhas do centro do Brasil, a Cidade de Goiás reverbera o espírito poético de sua ilustre moradora, Ana Lins dos Guimarães Peixoto Bretas (Cidade de Goiás, 20 de agosto de 1889 - Goiânia, 10 de abril de 1985), mulher, mãe e esposa, que soube esperar por 75 anos, cozendo doces e palavras, de suas dores, cores e amores, o lançamento de seu primeiro livro.

Sob o pseudônimo de Cora Coralina, a poetisa e contista foi apresentada ao mundo das artes pelas mãos de Carlos Drummond de Andrade. Tornou-se conhecida nacionalmente com a publicação, no ano de 1965, do seu livro "O Poema dos Becos de Goiás e Estórias Mais". Os versos colorem a sua terra natal, suas raízes de mulher que remove com suas mãos as pedras dos caminhos, que planta flores, que faz doces e imprime poemas de suas e outras histórias.

\begin{abstract}
Vive dentro de mim/ uma cabocla velha/ de mau olhado/ acocorada ao pé do borralho, olhando pra o fogo [...] Vive dentro de mim/ a lavadeira do rio Vermelho. Seu cheiro gostoso dágua e sabão [...] Vive dentro de $\mathrm{mim} / \mathrm{a}$ mulher cozinheira. Pimenta e cebola. Quitute bem feito [...] Vive dentro de mim/ a mulher proletária/ bem linguaruda/ desabusada, sem preconceitos [...] Vive dentro de mim/ a mulher da vida/ Minha irmãzinha [...] tão desprezada,/ tão murmurada (CORALINA, 2008, p. 253).
\end{abstract}

A mulher andeja e multifacetada que ao se apaixonar vai com o futuro esposo para o interior do estado de São Paulo, onde gera seus filhos, vende livros, colabora em jornais no interior de São Paulo, auxilia as forças militares na Revolução Constitucionalista e defende a criação de um partido feminista (PEREGRINO, BEZERRA, 2009). Com o falecimento de seu marido, volta para a Cidade de Goiás, em sua Casa Velha da Ponte para vender doces, artesanalmente elaborados e cristalizados, como forma de manutenção da vida e labor.

Tal como a elaboração de seus doces, Cora Coralina compõe em sua máquina de escrever os contos, advindos da escuta por entre os becos de sua amada cidade. A poetisa entalha nas palavras, como pedra bruta, as impressões de todas as mulheres incorporadas em seu eu-poético "entre pedras que me esmagavam levantei a pedra rude de meus versos" (CORALINA, 1998, p.13). Cristaliza em versos a mulher simples e intensa do coração do Brasil, à brada voz, com o seu lirismo canta a terra, a água e o ar.

Dona de uma escrita singular, Cora Coralina ${ }^{1}$ foi reconhecida e aclamada como uma das maiores escritoras brasileiras, 
trazendo nas veias o sangue de Olavo Bilac e Luiz Ramos de Oliveira Couto, Cora Coralina alcançou o respeito de autores como Monteiro Lobato e Carlos Drummond de Andrade, que após ler seus poemas, publicou um elogioso artigo no Jornal do Brasil, em 1980. A partir daí, a autora passou a conquistar o reconhecimento de todo o Brasil (PEREGRINO, BEZERRA, 2009, p. 8).

A intelectual, que se compreendia em essência como doméstica, cozinheira, doceira, escrevia "impelida por um impulso incontrolável" (CORALINA, 1994, p. 83) que pulsava em seus versos, irrigados pelo coral de seu sangue e de sua trajetória tão ricamente vivida. As cores, que em suas veias corriam, emanavam também a solidão,

Sozinha/ Na estrada deserta,/ sempre a procurar/ o tempo perdido que ficou para trás../ Do perdido tempo/ Do passado tempo/ escuto a voz das pedras:/ Volta...Volta... Volta.../ E os morros abriam para mim/ imensos braços vegetais (CORALINA, 1994, p. 84).

Ana Lins faleceu no dia 10 de abril de 1985, mas ficou Cora Coralina, suas cores e as mulheres que nela habita. Em sua essência, ela ouviu: "Escuto leve batida./ Levanto descalça, abro a janela devagarinho./ Alguém bateu?/ É a lua-luar que quer entrar" (CORALINA, 1994).

E, então, ela entra, descalça, mulher comum, mulher do mundo, na vida daqueles que versam palavras. E, a partir de suas letras, emergem pesquisas de mestrado e doutorado, em busca dos fenômenos e da compreensão das facetas literárias da autora, em especial nas áreas de Linguística, Letras e Literatura, em universidades espalhadas por todo o país.

$\mathrm{Na}$ ânsia de senti-la pulsar, surge a premência da criação do Museu Casa de Cora Coralina. Inaugurado no dia 20 de agosto de 1989, data comemorativa dos 100 anos de nascimento da escritora. Inicialmente, o Museu Casa guarda e preserva histórias e memórias de vida da autora, apresentando seu espaço de devaneio e objetos, que denotam seu modo simples de laborar a vida.

Da materialidade que desvela o imaterial do Museu Casa de Cora Coralina, propõe-se descortinar neste trabalho a experiência e as sensações produzidas a partir da aplicação do projeto expográfico incorporado à exposição museológica, pelos pesquisadores do Laboratório de Pesquisa, Desenvolvimento e Inovação em Mídias Interativas da Universidade Federal de Goiás - MediaLab - UFG.

Nesse sentido, o fenômeno a ser explorado nesse artigo visa estabelecer relações entre os escopos técnicos e poéticos do projeto expográfico, por meio da releitura dos padrões tecnológicos que manifestam a simbiose entre as letras, versos, poesias e prosas da autora. 
Trata-se de descortinar a interface que medeia o corpus imaterial da escritora, com os elementos materiais que representam seu espaço em vida, realizando uma ponte "que conecta, liga duas margens" (ROCHA, 2016, p. 2) do mundo da poetisa Cora Coralina e os visitantes, suas experiências ante aos aparatos tecnológicos que promovem sensações a partir da máquina de escrever, da chaleira, da bica do porão da casa, dos murmúrios das árvores do pomar de Cora.

Como caminhantes que vislumbram um trajeto de vozes dissociantes na Cidade de Goiás, nos retratos da cor local, o percurso metodológico transita por entre ruelas, becos e bicas, produzindo fervuras, murmúrios, ecoando e escoando poesias. Busca-se transcender, tendo como mediação a tecnologia, suas potencialidades, sua interatividade. E assim, sentir, ver e ouvir o triângulo da vida em Cora Coralina.

Triângulo da vida: caminhos e vozes dissonantes

No intuito de sentir, ver e ouvir Cora Coralina inflexionada em primeira pessoa é que se convida a refletir a tecnologia enquanto mediação presente nas dissociantes vozes por meio do ar, da água e da terra, tríade constituinte do triângulo da vida. Dessa forma, no caminhar pelos becos da Cidade de Goiás, vislumbra-se tecnologias diversas em tempos históricos e culturais distintos, sendo possível a interface do presente e do passado em justaposição, lendo nas entrelinhas dos espaços e ares no Museu Casa de Cora Coralina em narrativas e poesias.

A compreensão dos elementos citados é relevante na leitura ontológica categorizada como poética-narrativa das obras de Cora para além de estética, mas no sentido da experiência, do desejo dos caminhantes dos becos de Goiás conceberem em suas veias internas e expor na externalidade de seu ser versos materializados no concreto real e pensado do Museu Casa de Cora Coralina. Nesse sentido, Paraguai e Rocha (2016, p. 2.863) apontam que "o aspecto holístico da experiência, entendido aqui na sua completude, pressupõe a compreensão já clássica de que o todo é maior que a junção de suas partes".

Consoante ao aspecto de escrita da poetisa, a linguagem informal se coloca na articulação forma-conteúdo subjetivo, como sobressalta Krol e Poletto (s/d, p. 5) "essa linguagem informal está associada ao desejo de registrar imagens de um tempo e de um espaço, pois essa linguagem traz as marcas desse espaço e desse tempo", como se observa no poema "O triângulo da vida" (1984):

\footnotetext{
Minha bisavó não falava errado, falava no antigo,

Ficou agarrada às raízes e desusos da linguagem

E eu assimilei seu modo de falar.

Ela jamais pronunciou "metro", sempre "côvado" ou "vara".

Nunca disse "travessa" e sim "terrina", rasa ou funda que fosse,

Nunca dizia "bem vestido", falava - "janota" e "fama" era "galarim".

Sobraram na fala goiana algumas expressões africanas, como Inhô, [Inhá,
} 
Inhora, Sus Cristo.

Muito longe a curretela dos negros

Que seus descendentes vão corrigindo através de gerações

(...)

Assim, as vozes e linguagens poéticas aclamadas na história da vida da poetisa submerge do passado, ressoando nos becos de Goiás, em um primeiro instante, de sentidos e olhares dos caminhantes em todos os tempos. O triângulo da vida e seus elementos emergentes das vozes de "Aninha" nas linhas traçadas delineiam o movimento retroliterário necessário à sobrevivência das cores emanadas intrinsecamente pelas poesias de Cora Coralina, que não se apegava em métricas e rimas, e na simplicidade da sua escrita vivenciava a liberdade.

Esse desenho de uma escrita (des)compromissada e livre possibilita o pensar as cores emanadas da poesia de "Aninha", bem como de seus doces, adocicados em metafóricos tachos de realidade no contraste dos contextos, apresentando o caminho urbano e o rural. Aninha em cores! Cores na imensidão da consciência dos caminhantes que, vagarosamente, transitam pelos becos de Goiás e encontram raízes no Museu Casa de Cora Coralina.

Na material imaterialidade de Serra Dourada, na cidade de Goiás, Cora viveu os contextos que atravessam a linha do tempo, refletindo as palavras que se diferenciam de acordo com os personagens em suas vozes que deságuam nas leituras e escritas e respingam nas experiências.

Os caminhantes que entoam um trajeto de vozes dissociantes na Cidade de Goiás apresentam a vida que, por sua vez, acaba retornando à metafórica gênese bíblica ao afirmar que a terra não tinha nada (BÍBLIA, GÊNESIS, s/d). No entanto, viemos e voltamos para a terra ríspida, respirando fortuitamente o ar poético inspirado no criado ao lado da cama da poetisa e aprofundando no oceano das águas da bica e da tonalidade marrom do Rio Vermelho em nossas entranhas culturais e biológicas. De nossa genética, magnetizam-se os elementos mencionados e em sua junção são geradas forças distintas nas vozes internas, em aposta de cores de Cora.

Eis que da ideia vazia da terra apresentam-se os elementos centrais de sua poiesis: ar, água e terra. Elementos que de forma magnética se integram ao ser em sua vivência e seu cotidiano, trazendo a experiência (ví)vida e a identidade poética das escritas de Cora em cores em seu caminho poético.

Dito isso, retorna-se a questão da tecnologia enquanto artefato cultural no itinerário do Museu Casa de Cora Coralina, em como ela é inscrita nessa retórica da poesia enquanto simbiose entre as letras, versos, prosas e mídias e, como já ressaltado, além dos caminhantes que vislumbram um trajeto de vozes articuladas à tecnologia poética na Cidade de Goiás. A partir da interatividade e da tecnologia se observa poesia no quintal repleto de árvores, no quarto refletido na parede, na corrente água da bica localizada no porão e no vapor adocicado com poesias e tecnologias. Rocha e Venturelli (2018) dissertam que a poesia transita nos tempos e espaços da 
cozinha, da bica de água límpida, na parede do quarto: “... os versos bailam e se dissolvem na estrutura da casa. E assim se faz o triângulo da vida: com versos na água, no ar e na terra" (p. 3).

Seus doces, em tachos rosados de cobre, saboreados nas palavras de Cora Coralina, refletem o aroma deste espaço museológico expográfico, perfazendo em suas escritas a visibilidade do ar, da água e da terra.

\section{Museu Casa de Cora Coralina: Tecnologia poética}

Os museus passam por um processo de evolução, como reflexo do contexto contemporâneo, diante de novos espectadores críticos e sensíveis. Os museus contemporâneos, desse modo, propõem inúmeros desafios para o fortalecimento dessa instituição, bem como formatação de ações para proporcionar experiências que gerem dialogicidade a partir da percepção, interação, interpretação, descobertas, cognição e, mesmo, entretenimento. De acordo com Rodrigues (2017):

\footnotetext{
Os museus bradam e conclamam pela dinâmica do movimento, do fluxo de histórias, memórias, lembranças e esquecimentos, germinando uma girândola de intervenções sensoriais, cognitivas e afetivas, que serviriam para expressar o museu em sua configuração (p. 85).
}

Assim, na contemporaneidade, alguns museus têm buscado potencializar conhecimento, diálogo e interação, a partir de intervenções distintas artísticas."Tais espaços têm sido mediados como interface público-arte como culminância de processos de produção e exposição de trabalhos, tratando de questões relativas à imagem como lugares de experiência, no campo da Cultura Visual" (RODRIGUES, 2017, p. 87).

0 que se percebe, atualmente, são processos de transformação, em que o museu ultrapassa seu caráter de guarda da história, assinalando uma função cultural de resgate, comunicação e contemplação, por meio de imagens, em convergência com mídias interativas, revisando o papel da imagem e da visualidade na exposição da cultura visual contemporânea.

Neste artigo, o estudo versa o Museu Casa de Cora Coralina, ao apresentar seu projeto expográfico, como vetor da nova museologia, no comprometimento com a dialogicidade, a partir do reconhecimento do visitante como elemento de relevância na constituição de experiências singulares. A equipe Media Lab/UFG atuou no projeto de mídias interativas para o Museu Casa de Cora Coralina com a compreensão de uma casa envolta em poesia, em cada detalhe de sua intervenção, com a ênfase do museu ser interpretado e atualizado com um respirar na contemporaneidade. 
Os poemas da poetisa Cora mantiveram a temática de seus lugares de origem: a sala da escrita, a cozinha e a bica, contemplando nesses três espaços o triângulo da vida.

Para cada espaço apresentado, as escritas fluem com uma dinamicidade envolvida aos elementos cotidianos da autora, com uma carga semântica dialógica, amparada por uma polifonia.

A relação água, ar e terra encontrava, nestes lugares, seu sentido mais pulsante. $O$ ar da cozinha, umidificado pela poesia que enche os pulmões de versos; a água da bica, que faz escorrer versos para o rio, e a terra da parede da sala de escrita, que ultrapassa molduras e faz repousar, em sua extensão, os versos que passam a constituir a casa, sua estrutura e paredes (PARAGUAI; ROCHA, 2016, p. 2871).

Na sala, a partir de uma máquina de escrever rente à parede, o poema "O canto da terra" se espraia, subindo à parede a partir da máquina, numa perspectiva de envolvimento poético por todo o ambiente. Na cozinha, a poesia é reverberada pelo ar, pelo vapor da chaleira, letras do poema "Quem é você" são alastradas, penetrando as vias aéreas de todos os que ali visitam. Escoando pela bica ao lado da casa, o poema "A casa velha da ponte" serpenteia pela água, que o conduz até o Rio Vermelho.

As poesias incorporadas ao ambiente revestem os espaços pela tríade água, terra e ar - triângulo da vida sustentado por Cora Coralina - em uma atmosfera poética e reflexiva. Uma constituição que evoca a gênese da inspiração literária da poetisa, por meio de mídias interativas que se desdobram em experiências corriqueiras dos afazeres da escritora, com performances que traduzem um museu poético.

A arte repensada por intervenções tecnológicas criativas, com possibilidades de vivenciar uma visitação com traçados de novos e significativos planos de experiências, pelo conhecimento das obras de Cora, de seus locais de produção e inspiração, diante de cada intervenção meticulosamente estudada pelos profissionais que desenvolveram essa pesquisa-intervenção. Um projeto que traz à tona Cora em seu mais atuante modo de vida, por meio de sua produção literária.

Desse modo, esse museu, na atualidade, representa um descortinar o pensamento da instituição museológica estática de pesquisa e preservação somente. Conforme Rodrigues (2017, p. 177), "um desafio dos museus na contemporaneidade é a noção estática estar sendo substituída pela ideia de movimento nas práticas institucionais museológicas". No caso do exemplo deste estudo, um museu casa em vida que respira poesia pelo ar evacuado pela chaleira da cozinha, pela terra nas paredes que brotam poemas, na alusão de uma extensão do papel na escrita da máquina de datilografia e na fluidez da água da bica com letras poéticas que balançam ao ritmo das irregulares e ínfimas ondas. 
De fato, os museus conclamam por uma postura ativa, diante de multi possibilidades, no caso do museu em análise, as intervenções tecnológicas, estéticas e ontológicas com a participação do contexto do sentido de suas obras literárias, possibilitam experiências sensórias. A visitação ao museu apresenta uma perspectiva além da contemplação pelas ambientações e instalações tecnológicas, que direcionam para uma singularização na experiência. E, segundo Rocha (2018):

O conceito de experiência se sobressai no trabalho, que parte da definição poética da vida de Cora Coralina, para emergir. Terra, água e ar: eis o triângulo da vida, definiu a autora vilaboense. Baseado nesse triângulo, as concepções articularam tecnologia e poesia, para poetizar o ar, a água e a terra, tendo a poesia como elemento da vida da poetisa. Esse lastro se vinculou à experiência de ser poesia nos elementos definidos pela autora (p. 28).

$\mathrm{O}$ autor $^{2}$ considera a cultura uma área pujante para a construção de experiências, não se restringindo ao campo da arte, possibilitando outros domínios, na captura e criação de novas correlações. No Museu Casa de Cora Coralina, a tecnologia permite a possibilidade de compreensão das muitas outras visualidades, num processo de sinergias sensórias, que compõem o mundo contemporâneo.

A segunda etapa do projeto, inaugurada durante o 1o. Encontro museus-casas literários na cidade de Goiás em 2018, apresenta mais intervenções artísticas, além das já delineadas nesse escrito:

A segunda etapa foi dedicada aos sons: uma parede que sussurra poesia, um jardim que ecoa os versos coralinos e a iluminação do quintal, que recebeu o Cora Café. Ainda, nesta etapa, está em estudo a inserção de cheiros pelo museu, pesquisa de pós-doutorado da artista pesquisadora Luisa Paraguai, realizada no Media Lab / UFG sob supervisão do professor Cleomar Rocha (ROCHA, 2019, s/p).

As contribuições da prática fenomenológica no sujeito que vê, sente e percebe, vinculadas ao conceito de experiência de Dewey permitem que este estudo se ancore na Pós-fenomenologia. O que Ihde (2012) elucida a respeito da Pós-fenomenologia é sua estruturação para um contexto atual com todo o legado tracejado pela Fenomenologia e pelo Pragmatismo.

Ihde (2012) insere o termo Pós-fenomenologia como a junção conceitual do Pragmatismo de John Dewey e da Fenomenologia de Edmund Husserl, com olhares em suas heranças. Para o autor, a Pós-fenomenologia é uma corrente de pensamento que problematiza aspectos não soluciona- 
dos pela Fenomenologia, especialmente quando se trata de transformações sociais e em novos contextos histórico-culturais na contemporaneidade, em situações que não pertenciam à época daqueles filósofos, mas sem renunciar ao projeto fenomenológico, na busca de responder questões do nosso próprio tempo e espaço (RODRIGUES, 2017, p. 111).

A autora, ancorada em Ihde (2012), compreende que diferentes modos de experiência são vivenciados a partir do pragmatismo, onde novos campos de possibilidades emergem.

A arte no Museu Casa de Cora Coralina afeta a consciência pelas experiências singulares por meio da colheita de sentidos, concebendo uma dialogicidade, como um espaço de relações, entre os visitantes e os objetos que fazem parte desse contexto. A produção de intervenções tecnológicas no museu faz com que a recepção seja cada vez mais marcada por uma simultaneidade de sensações coradas.

\footnotetext{
1 A partir do reconhecimento nacional, Cora Coralina é agraciada com o Troféu Jaburu, oferecido pelo Conselho de Cultura do Estado de Goiás e ao participar do $1^{\circ}$ Encontro das Mulheres nas Artes, recebe o Prêmio de Poesia. Em 1982, é escolhida Personalidade Cultural pela União Brasileira de Escritores, no Rio de Janeiro e, com a publicação de "Vintém de Cobre - meias confissões de Aninha" (1983) recebe o prêmio Juca Pato, oferecido pela União Brasileira dos Escritores e pela Folha de São Paulo. Com a imanência de seus versos e prosas se torna doutora Honoris Causa pela UFG. Em 1984 é escolhida, pela Organização das Nações Unidas para a Agricultura e Alimentação (FAO), como símbolo brasileiro do Ano Internacional da Mulher Trabalhadora e ainda, no mesmo ano recebe o Grande Prêmio da Crítica, na categoria Literatura, da Associação Paulista de Críticos de Arte - APCA e ingressa na Academia Goiana de Letras.

2 Coordenador do projeto baseado no conceito do Museu Casa de Cora Coralina como poesia viva.
}

\section{Referências}

CORALINA, Cora. Meu livro de cordel. São Paulo: Global. 1994.

CORALINA, Cora. Vintém de cobre: meias confissões de Aninha. 2. ed. Goiânia, Ed. da Universidade Federal de Goiás. 1984.

CORALINA, Cora. O Poema dos Becos de Goiás e Estórias Mais. 1965.

CORALINA, Cora. Coleção Melhores Poemas. 3 ed. São Paulo: Global. 2008.

IDHE, Don. Pragmatism and Phenomenology. In: Experimental Phenomenology. Albany: State University of New York (p. 115 - 128). 2012.

KROL, Évelin da Silva; POLETTO, Juarez. s/d. Função social em "vintém de cobre: meias confissões de aninha", de Cora Coralina. Disponível em: https://periodicos.utfpr.edu.br/rl/ article/download/2328/1464. Acesso em: 25 jul. 2019. 
PARAGUAI, Luisa; ROCHA, Cleomar. Pesquisa-intervenção: traçados dos planos de experiências. In: 25o. Encontro da ANPAP: Arte: seus espaços e/em nosso tempo. Porto Alegre, RS. 26 a 30 de setembro de 2016 .

PEREGRINO, Júlia. BEZERRA, Costa. Cora Coralina, coração do Brasil. São Paulo: Museu da Língua Portuguesa. 2009.

ROCHA, Cleomar. Sobre pontes, janelas e peles: cultura, poéticas e perspectivas das interfaces computacionais. $2^{\mathrm{a}}$ ed. Goiânia: Media Lab / CIAR UFG / Gráfica UFG. 2016.

ROCHA, Cleomar. A poesia viva como legado. In: Vintém de cobre. Goiânia: Kelps. 2018.

ROCHA, Cleomar de Sousa. Verbivocovisual: Museu Casa de Cora Coralina. In ANAIS do 280.

Encontro Nacional da Associação Nacional de Pesquisadores em Artes Plásticas. Goiás-GO: Anpap. 2019.

ROCHA, Cleomar; VENTURELLI, Suzete. 2018. Engenhando nosso futuro: arte e sociedade. Cienc. Cult., São Paulo, v. 70, n. 2, p. 41-46. Disponível em: http://cienciaecultura.bvs.br/scielo.php?script=sci_arttext\&pid=S0009-67252018000200012\&lng=en\&nrm=iso. Acesso em: 25 jul. 2019.

RODRIGUES, Olira Saraiva. Museus em REDESenvolvimento? 2017. 200 f. Tese (Doutorado) - Faculdade de Artes Visuais. Programa de Pós-graduação em Arte e Cultura Visual. Universidade Federal de Goiás, Goiânia. 2017. 